TẠP CHÍ KHOA HỌC ĐẠI HỌC TÂN TRÀO

ISSN: $2354-1431$

http://tckh.daihoctantrao.edu.vn/

\title{
Khả năng sử dụng ngôn ngữ của trẻ 5 - 6 tuổi trong việc chuẩn bị vào học lớp 1 ở trường tiểu học
}

\author{
Vũ Thị Kiều Trang ${ }^{a^{*}}$ \\ ${ }^{a}$ Truờng Đại học Tân Trào \\ *Email: baotrangvk@gmail.com
}

\section{Thông tin bài viết}

Ngày nhận bài:

$02 / 4 / 2018$

Ngày duyệt đăng:

$12 / 6 / 2018$

\section{Tì khoá:}

Khả năng, ngôn ngũu, chuẩn bi vào hoc lớp 1.

\section{Tóm tắt}

Nghiên cứu 280 khách thể gồm 110 trẻ mẫu giáo 5-6 tuổi; 40 giáo viên mầm non; 110 phụ huynh và 20 chuyên gia trong lĩnh vực giáo dục mầm non, thuộc 4 trường mầm non trên địa bàn Tỉnh Tuyên Quang cho thấy, khả năng sử dụng ngôn ngữ của trẻ 5-6 tuổi trong việc chuẩn bị vào học lớp 1 ở trường Tiểu học đạt trung bình. Trong đó, biểu hiện khả năng sử dụng lời nói để giao tiếp đạt mức độ cao nhất; khả năng nghe, hiểu lời nói trong giao tiếp ở vị trí thứ hai và khả năng hiểu biết ban đầu về việc đọc, viết có mức độ thấp nhất. Kết quả phản ánh đúng thực tiễn khả năng của trẻ em độ tuổi này và tác động của giáo dục cũng như vai trò của gia đình trong việc phát triển ngôn ngữ cho trẻ.

\section{1. Đặt vấn đề}

Trẻ em nói chung và trẻ 5 - 6 tuổi nói riêng là một thành phần trong nhóm xã hội yếu thế. Trẻ non nớt về thể chất, yếu đuối về tinh thần và dễ dàng gặp phải những khó khăn, trở ngại, những nguy hiểm trong cuộc sống. Chính vì vậy, việc trẻ 5-6 tuổi có thể vượt qua những khó khăn, sự yếu thế của bản thân để hòa nhập, tồn tại và phát triển trong môi trường xã hội là một điều hết sức quan trọng.

Trẻ 5-6 tuổi tiến vào bước ngoặt quan trọng của cuộc đời, đó là việc trẻ chuyển từ trường mầm non sang học tập ở trường Tiểu học. Giai đoạn này đánh dấu quá trình chuyển qua một lối sống mới với những hoạt động mới, vị trí xã hội mới, mối quan hệ mới của một người học sinh thực thụ. Đồng nghĩa với đó, trẻ chuyển sang hoạt động chủ đạo mới đó là hoạt động học tập thay thế cho hoạt động vui chơi ở trường mầm non. Giúp trẻ có được một tâm thế sẵn sàng, một hành trang đầy đủ về mặt kiến thức để có thể hoà nhập nhanh nhất với hành trình mới này cần đến sự chuẩn bị công phu và tỷ mỷ của người lớn. Chính vì điều này, từ năm học 20122013, Bộ giáo dục và đào tạo đã thực hiện chương trình phổ cập giáo dục cho trẻ mầm non 5 tuổi với mục đích tạo những điều kiện tối ưu nhất để chuẩn bị cho trẻ thích ứng với các hoạt động học tập ở trường Tiểu học bao gồm 4 nội dung cơ bản đó là: hoạt động phát triển thể chất, hoạt động phát triển nhận thức, hoạt động phát triển ngôn ngữ, hoạt động phát triển tình cảm và quan hệ xã hội [6]. Trong đó hoạt động phát triển ngôn ngữ cho trẻ nhận được rất nhiều sự quan tâm của phụ huynh và giáo viên mầm non.

Những biểu hiện về khả năng sử dụng ngôn ngữ của trẻ 5-6 tuổi bao gồm: khả năng nghe hiểu lời nói; khả năng sử dụng lời nói để giao tiếp; hiểu biết ban đầu về việc đọc, viết. Đây là những khả năng rất cần thiết và là tiền đề quan trọng để chuẩn bị cho trẻ vào học lớp 1 ở trường Tiểu học.

\section{Khách thể và phương pháp nghiên cứu}

\subsection{Khách thể nghiên cứu}

Tổng số khách thể khảo sát 280 người. Trong đó: 110 trẻ mẫu giáo 5 - 6 tuổi ( 55 trẻ nam, 55 trẻ nữ), 110 phụ huynh (của 110 trẻ 5 - 6 tuổi được lựa chọn), 40 giáo viên mầm non dạy lớp mẫu giáo 5 - 6 tuổi và 20 chuyên gia trong lĩnh vực giáo dục mầm non thuộc 4 
trường mầm non tại địa bàn Thành phố Tuyên Quang và huyện Chiêm Hoá tỉnh Tuyên Quang.

\subsection{Phuơng pháp nghiên cúu}

Phương pháp nghiên cứu: chủ yếu là phương pháp nghiên cứu tài liệu, điều tra bằng bảng hỏi, phương pháp quan sát, phỏng vấn sâu, thống kê toán học.

Thang đo: dựa vào tổng điểm $(\mathrm{T}$ ) của mỗi trẻ, điểm trung bình $(\mathrm{ÐTB})$ và độ lệch chuẩn (ĐLC) của mẫu nghiên cứu, trẻ được phân về 3 mức độ thích ứng: mức độ cao, mức độ trung bình và mức độ thấp. Phần mềm SPSS 20.0 được sử dụng để xử lý kết quả nghiên cứu.

\section{Kết quả nghiên cứu}

Kết quả nghiên cứu cho thấy ngôn ngữ của trẻ 5-6 tuổi có sự tương đồng giữa các khả năng: nghe hiểu lời nói; sử dụng lời nói để giao tiếp; hiểu biết ban đầu về việc đọc, viết.

\section{Bảng 1. Biểu hiện khả năng sử dụng ngôn ngữ của trẻ 5 - 6 tuổi}

\begin{tabular}{|l|c|c|c|c|}
\hline \multicolumn{1}{|c|}{ Kết quả đánh giá } & ĐTB & ĐLC động & Mức độ & Thứ bậc \\
\hline 1. Khả năng nghe, hiểu lời nói trong giao tiếp & 3,34 & 0,73 & TB & 2 \\
\hline 2. Khả năng sử dụng lời nói để giao tiếp & 3,44 & 0,54 & TB & 1 \\
\hline 3. Hiểu biết ban đầu về việc đọc, viết & 2,84 & 0,72 & TB & 3 \\
\hline Điểm trung bình chung & $\mathbf{3 , 2 1}$ & $\mathbf{0 , 5 5}$ & TB & \\
\hline
\end{tabular}

Ghi chú: Thấp: 1,0-2,61; Trung binh: 2,62-4,06; Cao: 4,07-5,0

Với ĐTB chung $=3,21$ và ĐLC 0,55 cho thấy biểu hiện khả năng sử dụng ngôn ngữ của trẻ 5-6 tuổi ở mức trung bình. Trong ba khả năng sử dụng ngôn ngữ của trẻ thì khả năng hiểu biết ban đầu về việc đọc, viết hạn chế hơn hai khả năng còn lại. Khả năng nghe, hiểu lời nói trong giao tiếp và khả năng sử dụng lời nói để giao tiếp có mức độ tương đồng nhau. Tuy vậy, mức độ chênh lệch giữa các khả năng này không đáng kể. Chúng ta có thể xem xét biểu hiện cụ thể của các khả năng này.

\subsection{Biểu hiện ở khả năng nghe, hiểu lời nói} trong giao tiếp

Trẻ 5-6 tuổi, đã biết sử dụng tiếng mẹ đẻ một cách thành thạo trong sinh hoạt hàng ngày [2]. Điều này được thể hiện thông qua ngôn ngữ mạch lạc của trẻ. Một trong những biểu hiện của ngôn ngữ mạch lạc đó chính là khả năng nghe hiểu lời nói trong giao tiếp. Việc nghe, hiểu lời nói là trẻ nghe và hiểu các từ, cụm từ khái quát, hiểu nội dung của từ ngữ thông qua các tác phẩm văn học, cao hơn nữa là trẻ phải hiểu được sắc thái biểu cảm của lời nói khi giao tiếp.

Bảng 2. Biểu hiện khả năng nghe, hiểu lời nói trong giao tiếp của trẻ 5-6 tuổi

\begin{tabular}{|l|c|c|c|}
\hline \multicolumn{1}{|c|}{ Kết quả } & ĐTB hiện & ĐLC & Mức độ \\
\hline $\begin{array}{l}\text { 1. Nhận ra được sắc thái biểu cảm của lời nói khi vui, buồn, tức, giận, ngạc } \\
\text { nhiên, sợ hãi. }\end{array}$ & 3,45 & 0,84 & TB \\
\hline 2. Nghe hiểu và thực hiện được các chỉ dẫn liên quan đến 2, 3 hành động. & 3,23 & 1,00 & TB \\
\hline $\begin{array}{l}\text { 3. Hiểu nghĩa một số từ khái quát chỉ sự vật, hiện tượng đơn giản, gần gũi } \\
\text { như: nhóm gia cầm, nhóm đồ dùng học tập... }\end{array}$ & 3,29 & 0,92 & TB \\
\hline $\begin{array}{l}\text { 4. Nghe hiểu nội dung câu chuyện, thơ, đồng dao, ca dao dành cho lứa tuổi } \\
\text { của trẻ. }\end{array}$ & 3,39 & 0,88 & TB \\
\hline Điểm trung bình chung & $\mathbf{3 , 3 4}$ & $\mathbf{0 , 7 3}$ & TB \\
\hline
\end{tabular}

Ghi chú: Thấp: 1,0-2,61; Trung binh: 2,62-4,06; Cao: 4,07-5,0

Kết quả khảo sát tại bảng 2 cho thấy, trong số những biểu hiện khả năng nghe, hiểu lời nói trong giao tiếp thì khả năng nhận ra được sắc thái biểu cảm của lời nói khi vui, buồn, tức, giận, ngạc nhiên, 
sọ hãi đạt mức độ cao nhất (ĐTB: 3,45). Như vậy, trẻ không những nghe, hiểu lời nói mà còn có thể nhận ra sắc thái biểu cảm của lời nói. Điều này cho thấy kinh nghiệm của trẻ trong giao tiếp bằng ngôn ngữ đã đạt ở một trình độ nhất định. Tuy nhiên, việc nghe hiểu và thực hiện được các chỉ dẫn liên quan đến 2, 3 hành động lại ở mức độ thấp nhất (ĐTB: 3,23; ĐLC: 1,00). Kết quả phản ánh thực tiễn: cho dù trẻ 5-6 tuổi đã có sự phát triển về trí nhớ và chú ý có chủ định nhưng trẻ vẫn bị hạn chế khi thực hiện những nhiệm vụ kém sự "thú vị”. Kết quả này cũng thể hiện sự chênh lệch tương đối cao giữa các trẻ (ĐLC: 1,00), cho thấy sự mất tập trung, ghi nhớ không ổn định chỉ xảy ra ở một số trẻ và có sự chênh lệch với những trẻ còn lại.

\subsection{Biểu hiện ở khả năng sử dụng lòi nói để giao tiếp}

Trong những biểu hiện khả năng sử dụng ngôn ngữ thì khả năng sủ dụng lời nói để giao tiếp có mức độ cao nhất (ĐTB: 3,44). Điều này chứng tỏ sự phát triển ngôn ngữ của trẻ diễn ra theo đúng quy luật phát triển lứa tuổi. Đối với trẻ mẫu giáo sự phát triển ngôn ngữ đạt tốc độ nhanh, đến 5-6 tuổi trẻ nắm được ngữ âm, ngữ điệu, phát triển ngữ pháp và ngôn ngữ mạch lạc [2]. Đặc biệt, với vốn từ phong phú, biết sử dụng các kiểu ngôn ngữ khác nhau khiến cho việc nghe hiểu lời nói, sử dụng lời nói và thực hiện những quy tắc thông thường trong giao tiếp trở nên dễ dàng hơn.

Kết quả biểu hiện khả sử dụng lời nói để giao tiếp của trẻ 5-6 tuổi được đánh giá ở mức trung bình. Điều này chứng tỏ trẻ đã bước đầu có vốn từ phong phú, có khả năng nắm bắt được cơ cấu ngữ pháp và cách diễn đạt ngôn ngữ. Trong đó biểu hiện việc sử dụng lời nói để bày tỏ cảm xúc, nhu cầu, ý nghĩ và kinh nghiệm của bản thân đạt mức độ cao nhất (ĐTB: 3,60).

Bảng 3. Biểu hiện khả sử dụng lời nói để giao tiếp của trẻ 5-6 tuổi

\begin{tabular}{|l|c|c|c|}
\hline \multicolumn{1}{|c|}{ Kết quả } & ĐTB hiện & ĐLC & $\begin{array}{c}\text { Mức } \\
\text { độ }\end{array}$ \\
\hline 1. Nói năng rõ ràng, mạch lạc. & 3,41 & 0,88 & $\mathrm{~TB}$ \\
\hline 2. Biết sử dụng các loại câu khác nhau trong giao tiếp như: câu hỏi, câu cảm thán... & 3,45 & 0.76 & $\mathrm{~TB}$ \\
\hline $\begin{array}{l}\text { 3. Sử dụng lời nói để bày tỏ cảm xúc, nhu cầu, ý nghĩ và kinh nghiệm của bản } \\
\text { thân như: con thích bạn Mai, con muốn đi chơi, con biết cách làm... }\end{array}$ & 3,60 & 0,71 & $\mathrm{~TB}$ \\
\hline 4. Sử dụng lời nói để trao đổi và chỉ dẫn bạn bè trong hoạt động. & 3,45 & 0,81 & $\mathrm{~TB}$ \\
\hline 5. Kể lại được nội dung chuyện đã nghe theo trình tự nhất định. & 3,28 & 0,91 & $\mathrm{~TB}$ \\
\hline 6. Biết cách khởi xướng cuộc trò chuyện. & 3,45 & 0,77 & $\mathrm{~TB}$ \\
\hline 7. Biết điều chỉnh giọng nói phù hợp với tình huống và nhu cầu giao tiếp. & 3,44 & 0,84 & $\mathrm{~TB}$ \\
\hline \multicolumn{1}{|c|}{ Điểm trung bình chung } & $\mathbf{3 , 4 4}$ & $\mathbf{0 , 5 4}$ & $\mathrm{TB}$ \\
\hline
\end{tabular}

Ghi chú: Thấp: 1,0-2,61; Trung binh: 2,62-4,06; Cao: 4,07-5,0

Qua thực tế trao đổi trò chuyện với trẻ cũng nhận thấy, có nhiều trẻ tự tin, hồn nhiên "bày tỏ" tình cảm, suy nghĩ của mình và rất mạnh dạn hỏi chuyện các nghiệm viên. Đây là một trong những điều kiện quan trọng giúp trẻ học tập tốt hơn khi vào lớp 1 .

\subsection{Biểu hiện ở khả năng hiểu biết ban đầu về việc} đọc, viêt

Trong các biểu hiện khả năng sử dụng ngôn ngữ của trẻ $5-6$ tuổi thì biểu hiện khả năng hiểu biết ban đầu về việc đọc, viết có mức độ thấp nhất (ĐTB: 2,84) và có sự phân loại rõ rệt hơn các biểu hiện khác. Trong 8 biểu hiện được đề cập thì có 3 biểu hiện ở mức độ thấp, còn lại ở mức độ trung bình. Đáng chú ý là có tới 5 biểu hiện có ĐLC cao trên 1,00 , điều này chứng tỏ có độ chênh lệch lớn giữa từng trẻ với nhau trong việc chuẩn bị đọc, viết. 
Bảng 4. Biểu hiện khả năng hiểu biết ban đầu về việc đọc, viết của trẻ 5 - 6 tuổi

\begin{tabular}{|l|c|c|c|}
\hline \multicolumn{1}{|c|}{ Kết quả } & ĐTB hiện & ĐLC & Mức độ \\
\hline 1. "Đọc" theo truyện tranh đã biết & 2,88 & 1,14 & $\mathrm{~TB}$ \\
\hline 2. Kể chuyện theo tranh & 2,81 & 0,98 & $\mathrm{~TB}$ \\
\hline 3. Biết chữ viết có thể đọc và thay cho lời nói & 2,45 & 1,14 & $\mathrm{~TB}$ \\
\hline $\begin{array}{l}\text { 4. Biết dùng các ký hiệu hoặc hình vẽ để thể hiện cảm xúc, nhu cầu, ý nghĩ và } \\
\text { kinh nghiệm của bản thân }\end{array}$ & 2,25 & 1,12 & $\mathrm{~TB}$ \\
\hline 5. Bắt chước hành vi viết và sao chép từ, chữ cái & 2,86 & 1,00 & $\mathrm{~TB}$ \\
\hline 6. Biết tự "viết" tên của bản thân mình theo cách của riêng mình & 2,49 & 1,24 & $\mathrm{~TB}$ \\
\hline 7. Biết "viết" chữ theo thứ tự từ trái qua phải, từ trên xuống dưới & 3,42 & 0,90 & $\mathrm{~TB}$ \\
\hline 8. Nhận dạng được chữ cái trong bảng chữ cái tiếng Việt & 3,56 & 0,65 & $\mathrm{Cao}$ \\
\hline \multicolumn{1}{|c|}{ Điểm trung bình chung } & $\mathbf{2 , 8 4}$ & $\mathbf{0 , 7 2}$ & TB \\
\hline
\end{tabular}

Ghi chú: Thấp: 1,0-2,61; Trung bình: 2,62-4,06; Cao: 4,07-5,0

Có một thực tế phản ánh rất rõ nét trong kết quả nghiên cứu đó là việc trẻ có thể nhận dạng được chĩ cái trong bảng chũ cái tiếng Việt là biểu hiện có mức độ cao nhất (ĐTB: 3,56). Kết quả này có được do xuất phát từ quan điểm trẻ phải biết chữ, biết số trước khi vào lớp 1 nên mọi sự nỗ lực của gia đình, nhà trường và bản thân đứa trẻ được tập trung để giải quyết nhiệm vụ này. Trò chuyện với phụ huynh chúng tôi nhận thấy, có đến $90 \%$ cho rằng việc biết chữ là cần thiết trước khi con vào lớp 1 . Cho nên có nhiều phụ huynh đã cho con đi học trước để chuẩn bị cho con tự tin và vững vàng hơn cho giai đoạn tiếp theo. Còn đối với giáo viên mầm non thì coi đây như "áp lực", là một nhiệm vụ quan trọng nhất trong công việc dạy trẻ lứa tuổi này. Bên cạnh đó việc dạy trẻ biết "viết" chĩ theo thú tư tù trái qua phải, tù trên xuống duới cũng được rèn rũa tương đối kỹ (ĐTB: 3,42). Mặc dù theo quy định thì trẻ chưa phải tập tô, viết, nhưng hầu như trẻ vẫn được cha mẹ hoặc có nơi là cả cô giáo hướng dẫn tập viết, tập tô theo nét chấm mờ...Trong khi đó, hàng loạt những biểu hiện cần thiết khác như: có thể "đọc" theo truyện tranh đã biết; biết dùng các ký hiệu hoặc hình vẽ để thể hiện cảm xúc, nhu cầu, ý nghĩ và kinh nghiệm của bản thân; biết tụ "viết" tên của bản thân minh theo cách của riêng minh thì trẻ lại có kết quả thấp hơn và có độ chênh lệch cao giữa từng trẻ với nhau vì trẻ ít được quan tâm hướng dẫn hơn.

\section{Kết luận}

Như vậy, khả năng sử dụng ngôn ngữ của trẻ 5-6 tuổi tuy chỉ đạt mức độ trung bình, nhưng đã phản ánh đúng thực tiễn khả năng của trẻ em độ tuổi này và tác động của giáo dục cũng như vai trò của gia đình trong việc phát triển ngôn ngữ cho trẻ. Kết quả trên cũng phù hợp với kết quả điều tra từ giáo viên mầm non: có $50 \%$ giáo viên mầm non cho rằng trẻ có khả năng nghe, hiểu lời nói trong giao tiếp đạt mức độ cao; $55 \%$ cho rằng trẻ có khả năng cao trong việc sử dụng lời nói trong giao tiếp; trong khi đó chỉ có $37,5 \%$ cho rằng trẻ có mức độ tốt hơn ở khả năng hiểu biết ban đầu về đọc, viết. Trong các biểu hiện nội dung chuẩn bị cho trẻ $5-6$ tuổi vào lớp 1 ở trường Tiểu học thì việc chuẩn bị về khả năng sử dụng ngôn ngữ có những đòi hỏi khó hơn, các nội dung biểu hiện gần với hoạt động ở trường Tiểu học nhất. Do đó, việc còn có trẻ hạn chế ở lĩnh vực này là điều hiển nhiên. Việc hiểu rõ nguyên nhân, tìm ra hướng khắc phục để trẻ có khả năng sử dụng ngôn ngữ tốt hơn và phù hợp với trẻ hơn trong các hoạt động chuẩn bị đến trường Tiểu học là việc làm cần thiết và có ý nghĩa.

Đối với trẻ mẫu giáo sự phát triển ngôn ngữ đạt tốc độ nhanh, đến 5-6 tuổi trẻ nắm được ngữ âm, ngữ điệu, phát triển ngữ pháp và ngôn ngữ mạch lạc [2]. Đặc biệt, với vốn từ phong phú, biết sử dụng các kiểu 
ngôn ngữ khác nhau khiến cho việc nghe hiểu lời nói, sử dụng lời nói và thực hiện những quy tắc thông thường trong giao tiếp trở nên dễ dàng hơn khi trẻ bước vào học lớp 1 ở trường Tiểu học.

\section{TÀI LIỆU THAM KHẢO}

1. Phạm Thị Đức (1991), Chuẩn bị tâm lý cho trẻ vào lớp 1 , Tạp chí nghiên cứu giáo dục, số tháng 12 ;

2. Dương Thị Diệu Hoa (chủ biên) (2012), Giáo trình Tâm lý học phát triển, Nxb Đại học Sư phạm, Hà Nội;

3. Vũ Thị Nho (1998), Một số đặc điểm về sự thich nghi với hoạt động học tập của học sinh đà̀u bậc tiểu học, Tạp chí Tâm lý học số 5, tr 28-34;

4. Quyết định 239/QĐ-TTG của Thủ tướng Chính phủ ngày 09/02/2010, Quyết định phê duyệt đề án Phổ cập giáo dục mầm non cho trẻ 5 tuổi giai đoạn 2010-2015;
5. Đinh Hồng Thái (2013), Giáo trình phát triển ngôn ngũ tuổi mầm non, Nxb Đại học Sư phạm, Hà Nội;

6. Thông tư số 23/2010/TT-BGDĐT ngày 23/7/2010 của Bộ trưởng Bộ Giáo dục và Đào tạo về việc ban hành quy định về bộ chuẩn phát triển trẻ em 5 tuổi;

7. Trần Thị Ngọc Trúc (2008), Cần chuẩn bị nhũng gì cho trẻ vào lóp một, Nxb tổng hợp Thành phố Hồ Chí Minh;

8. Nguyễn Ánh Tuyết (chủ biên) (1999), Chuẩn bị cho trẻ 5 tuổi vào trường phổ thông, Nxb Giáo dục, Hà Nội;

9. Nguyễn Ánh Tuyết (chủ biên) (2014), Tâm lý học trẻ em lúa tuổi mầm non, Nxb Đại học Sư phạm, Hà Nội.

\section{The ability of using language of 5-6 years old children in the preparation of enrolling grade 1 at primary schools}

\section{Vu Thi Kieu Trang}

\section{Article info}

Recieved:

02/4/2018

Accepted:

$12 / 6 / 2018$

Keywords:

Abilty; Language; Preparing activities to grade 1 .

\begin{abstract}
The reseach was conducted on 280 participants including: 110 preschoolers aged 5-6 years old; 40 pre-school teachers who are teaching kindergarten; 110 parents and 20 experts in the field of kindergarten education. The research carried out a survey in 4 preschools in Tuyên Quang province. The results of study showed that: The ability to use language of children aged 56 years old in the preparation of enrolling grade 1 at primary school was at average level. In addition, expression of ability to use language to communicate was at the fist level; listening ability and understandability in communication was at the second level and being acquainted with reading, writing was at the third level. The results reflected the real abilty of children at this age. It also showed the impact of education and the role of family on developing children laguage.
\end{abstract}

